\title{
Organizational Approaches to Drug Law Enforcement by Local Police Departments in the United States: Specialized Drug Units and Participation in Multi-Agency Drug Task Forces
}

\author{
Robert M. Lombardo \\ Loyola University Chicago, rlombar@luc.edu \\ David E. Olson \\ Loyola University Chicago, dolson1@luc.edu
}

Follow this and additional works at: https://ecommons.luc.edu/criminaljustice_facpubs

Part of the Criminology and Criminal Justice Commons

\section{Recommended Citation \\ Lombardo, RM, and David E. Olson. (2009). "Organizational Approaches to Drug Law Enforcement by Local Police Departments in the United States: Specialized Drug Units and Participation in Multi-Agency Drug Task Forces." Justice Research and Policy, Volume 11, 2009. Available at http://dx.doi.org/10.3818/ JRP.11.2009.45}

This Article is brought to you for free and open access by the Faculty Publications and Other Works by Department at Loyola eCommons. It has been accepted for inclusion in Criminal Justice \& Criminology: Faculty Publications \& Other Works by an authorized administrator of Loyola eCommons. For more information, please contact ecommons@luc.edu.

\section{(c) $(\$) \ominus$}

This work is licensed under a Creative Commons Attribution-Noncommercial-No Derivative Works 3.0 License. (C) 2009 Justice Research and Statistics Association, Inc. 


\title{
ORGANIZATIONAL APPROACHES TO DRUG LAW ENFORCEMENT BY LOCAL POLICE DEPARTMENTS IN THE UNITED STATES: SPECIALIZED DRUG UNITS AND PARTICIPATION IN MULTI-AGENCY DRUG TASK FORCES
}

\author{
Robert M. Lombardo \\ David E. Olson \\ Loyola University, Chicago
}

\section{Abstract}

This paper examines the factors associated with the decision of local police departments in the United States to operate specialized drug units or to participate in multijurisdictional drug task forces. Combining data from the Law Enforcement Management and Administrative Statistics (LEMAS) Survey, the 2000 Census, and the Uniform Crime Report, we use both bivariate and multivariate methods to conduct the analysis. The findings indicate that county-level agencies, those with other formalized drug control efforts, high levels of violent crime, high degrees of task specialization and formalization, and high proportions of the resident population accounted for by renters were more likely to operate drug units, participate in multi-agency drug task forces, and allocate more officers per capita to these efforts.

This article is based on a paper prepared for the annual meeting of the American Society of Criminology, St. Louis, Missouri, November 12, 2008. 
Beginning in the mid-1980s with the passage of the Anti-Drug Abuse Acts of 1986 and 1988, the United States dedicated unprecedented resources to the control of illicit drug use, sales, and distribution. This new emphasis resulted in a dramatic increase in arrests for drug law violations, with the number of arrests for drug crimes almost doubling between 1985 and 1995, jumping from approximately 800,000 to almost 1.5 million (Bureau of Justice Statistics, 2005). By 2006, the annual number of arrests for drug law violations in the United States rose even further, exceeding 1.8 million (Federal Bureau of Investigation, 2007). The Office of National Drug Control Policy (2004, p. vi) estimates that the societal costs of drug abuse exceeded $\$ 180.9$ billion in 2002 , with nearly $\$ 9$ billion of these costs being borne by law enforcement agencies.

While most agree that controlling the drug problem requires involving the public health and educational systems, the criminal justice system is often the first to respond to emerging drug problems. How law enforcement agencies target drug law violations and drug markets varies from jurisdiction to jurisdiction, and can include everything from preventative efforts, such as the Drug Abuse Resistance Education program (DARE), to long-term, organized, and focused drug investigations involving specialized drug units within police departments and/or participation in multi-jurisdictional drug task forces. The goal of this research is to understand why local law enforcement agencies may operate their own specialized drug unit and/or participate in a multi-agency drug task force.

Drug control efforts are typically categorized as either demand reduction or supply reduction strategies. Demand reduction strategies aim at preventing the use of drugs through education and treatment, or deterrence through the risk of arrest and prosecution. Supply reduction strategies target the availability of drugs and involve a wide range of activities, including crop eradication, border interdiction, and street-level enforcement. The law enforcement response is typically hierarchical. The U.S. Drug Enforcement Administration (DEA), the Federal Bureau of Investigation (FBI), and the Department of Homeland Security investigate international and interstate trafficking rings, while state and local police departments typically interrupt the supply of drugs within states and at the street level. This hierarchical response has led many police departments to form specialized drug units to target mid-level drug wholesalers and dealers, many of whom would otherwise fall through the cracks because of the difference between federal practices and the street-level focus of uniformed law enforcement (Olson, 2005, p. 183).

Specialized police drug enforcement efforts typically take two forms: full-time specialized drug enforcement units within local police departments and participation in multi-agency drug task forces. In general, local law enforcement agency drug units limit their drug enforcement efforts to their specific geographic jurisdiction and carry out more sophisticated investigations than traditional patrol strategies involving on-view arrests. Multi-agency task forces also tend to carry out more sophisticated investigations and more targeted drug enforcement efforts, but carry out their investigative work across multiple participating jurisdictions. Despite the potential 
benefit of in-house drug units and drug task force participation as a law enforcement response to the drug problem, we know very little about how police departments decide which strategy to use, or how many officers they assign to these efforts.

Across local law enforcement agencies in the United States, the operation of specialized drug units and participation in multi-agency drug task forces is not that widespread. According to Hickman and Reaves (2006), only $18 \%$ of all local police departments in the United States in 2003 assigned officers full-time to a specialized drug enforcement unit within their agency, and only about one quarter $(23 \%)$ assigned officers full-time to a multi-agency drug task force. Still, the number of multi-agency drug task forces operating in the United States increased dramatically during the mid- to late-1980s largely because of the financial support provided by the federal government. The Anti-Drug Abuse Acts of 1986 and 1988 provided substantial amounts of money to state and local units of government to develop and operate multi-jurisdictional drug task forces. For example, between 1989 and 1994, the Bureau of Justice Assistance allocated more than $\$ 700$ million in federal block grant funds to drug task force efforts, accounting for $40 \%$ of the total law enforcement block grant distributions (Dunworth, Hayes, \& Saiger, 1997, p. 5).

The impact of the application of federal funds to the drug problem was substantial. State and local police agencies created more than 700 drug task forces between 1986 and 1993 (Coldren, 1993). By 1998, more than 1,000 drug task forces were operating in the United States, and more than 5,800 local police officers were assigned full time to these drug task forces (Reaves and Goldberg, 2000, p. iii). These 5,800 officers assigned to multi-agency drug task forces amounted to nearly twice the number of the agents employed by the Drug Enforcement Administration (Bureau of Justice Statistics, 2001). No less significant were the 13,600 officers assigned to specialized drug units within local police departments.

Further, recent research points to aggregate changes in the level of commitment to these drug units and task forces, at least among police departments serving large jurisdictions (more than 250,000 residents). For example, the average number of officers assigned to specialized drug units in big city police departments increased $43 \%$ between 1990 and 2000, to an average of 123 officers per department, although as a percentage of all officers these assignments actually decreased (Hickman \& Reeves, 2002, p. 7). A much smaller increase, however, was seen in the assignment of officers to drug task forces: The average number of officers per department climbed only $15 \%$ between 1990 and 2000, from an average of 13 to 15 full-time officers per department.

What factors determine whether a police department will operate a drug unit or participate in a multi-agency task force, and how many officers they assign to these efforts? One would expect that this decision would be based, at least in part, upon the size of the law enforcement agency. Those agencies that have a drug problem but are too small to support a dedicated drug unit would seem to be likely candidates for participation in a drug task force. Research, however, has shown that complex organizations make decisions for other than rational purposes. In 
his examination of the organizational and environmental factors surrounding the establishment of a gang unit within a Midwestern police department, Katz (2001, p. 66) found that the department created a gang unit because of institutional considerations-the pressures placed on police officials from various powerful elements within the community-and not a rational need.

The current study will investigate the characteristics associated with the operation of police drug units and participation in multi-agency drug task forces across local law enforcement agencies in the United States. Drug units were chosen for two reasons. First, they represent a response to a contemporary police problem. Second, unlike police gang units, little research has been conducted into the establishment of police drug units. Although little attention has been paid to the factors associated with formal, organizational responses to drug enforcement by local law enforcement agencies, there is a substantial body of literature that has examined the factors that affect the organizational features of police departments.

\section{Literature Review: Factors Affecting Organizational Features of Police Departments}

Ever since the Wickersham Commission (1931) called for the removal of politics from policing, law enforcement agencies throughout the United States have utilized organizational theory to improve their operations. From the early use of principles of scientific management, to modern, computerized command and control techniques, police agencies have ceaselessly worked to provide better service to the public. One of the most common methods of improving police service has been the use of differentiation. Differentiation refers to the subdivision of responsibilities. Police departments have routinely used task specialization, division of labor, and hierarchical organization to increase the effectiveness and efficiency of their operations.

In his pioneering study of work organizations, Blau (1970, p. 204) argued that increasing organizational size generates structural change among various dimensions. He identified these dimensions as occupational, functional, hierarchical, and spatial differentiation. According to Blau (1970, p. 216), explicit procedures exist within an organization for systematically subdividing the work necessary to achieve the organization's goals. Different tasks are assigned to different positions; specialized functions are allocated to various divisions and sections; branches are created in dispersed locations; and administrative responsibilities are subdivided among staff personnel and managers on various levels.

Langworthy (2002, p. 33) applied Blau's typology to police organizations. He defines occupational differentiation as the degree to which a police department employs specialists such as civilian 911 dispatchers, detectives, and other specially trained personnel. Functional differentiation is the degree to which police organizations respond to their task environment by creating specialized units, such as drug units. Hierarchical differentiation, also referred to as vertical differentiation, 
refers to the height of the organization-the rank structure. Spatial differentiation is the degree to which a police organization's territory is divided into units- the number of precincts and substations.

In an often-quoted review of the organizational literature, Maguire (1997, p. 550) adds three additional dimensions to the core elements of police organizational structure-centralization, formalization, and administration. He defines centralization as the extent to which the decision-making capacity of an organization is concentrated in a single individual or a small, select group. Langworthy (2002, p. 34) notes that centralization can take two forms: spatial and authority. Spatial centralization is similar to spatial differentiation, while authority centralization refers to the degree to which decision-making authority is distributed or attenuated. For example, the presence of a community policing program would indicate an attempt to decentralize decision-making authority within a police department. Formalization is simply defined as the degree to which an organization is governed by formal (written) rules. Lastly, administration refers to the proportion of available resources committed to administrative functions, such as the number of supervisors and the number of administrative support units.

Environmental factors also influence police organization. Research suggests that the size of the population served is related to the structure of many police departments. In an analysis published by the Bureau of Justice Statistics, Hickman and Reaves (2006, p. 15) found that the larger the population served, the more likely the jurisdiction was to employ both types of formal drug enforcement efforts-full-time drug units within the police department and full-time participation in a multi-agency drug task force. However, the authors did not examine the extent to which other agency or community characteristics were associated with the operation of a drug unit or participation in a drug task force.

Another factor shaping police organization is available resources. It takes money to establish a drug unit and to provide officers to participate in a drug task force. If we view police departments as rational organizations, we would expect that they would establish drug units in response to the drug problem in their jurisdiction, as long as they could afford the expense. Ratcliffe and Guidetti (2008, p. 10), however, write that the demands placed on the police have already far outstripped the resources available to them. They offer as evidence of declining resources the fact that police in the U. S. and the United Kingdom have looked to new methods to reduce crime, such as intelligence-led policing and computerassisted crime control strategies such as COMPSTAT, to compensate for their inability to increase the number of available officers. If local police departments do not have the resources to fund drug control efforts, one would assume that they would look to new strategies, such as participation in a multi-jurisdictional drug task force, in order to address the drug problem in their area.

Some have suggested that asset forfeiture could be used to support drug enforcement activities. In 2003, \$93,000 per sworn officer was spent in operational costs, but the median value of money, goods, and property received from asset 
forfeiture was only $\$ 7,000$ per agency (Hickman \& Reaves, 2006). Although forfeiture can be used to fund investigations, personnel salaries are generally the responsibility of the law enforcement agency. Additionally, a recent national study conducted by Worrall and Kovandzic (2008, p. 239) using LEMAS data found that crime control was more important to police agencies than revenue generation through asset forfeiture. This suggests that police departments do not enter narcotic enforcement to generate money.

We would also expect police departments to establish drug control efforts in response to the crime problem in their jurisdictions given the established relationship between drugs and crime. Drugs are related to crime in two ways. First, it is a crime to possess, sell, or distribute drugs unless licensed to do so. Second, drug use is related to crime because of the potential influence it can have on the user's behavior. For example, based on a 2004 survey of prison inmates, it was estimated that $17 \%$ of state prison inmates and $18 \%$ of federal inmates committed their current offense to obtain money for drugs (Mumola \& Karberg, 2006, p. 1). Further, violence has also been found to exist among those involved in the illicit drug trade. Writing for the Office of National Drug Control Policy, Spiess and Fallow (2000, p. 4) report that the drug trade causes violence because of the competition for drug markets and drug customers, disputes among individuals involved in the drug trade, and the tendency toward violence by the individuals who participate in the drug trade.

Like agency characteristics, community characteristics have also been found to be related to the structure of police organizations and levels of crime in communities. One such characteristic is population density. The role of population density in the generation or suppression of crime has been the subject of debate for some time (Harries, 2006, p. 1). The classic argument is that high density leads to higher residential crime rates. There are more residential burglaries, domestic assaults, larcenies, and auto thefts where there are more people and more things to steal. More crime leads to more police. On the other hand, densely populated areas offer natural surveillance that has the effect of inhibiting violent crime, in that witnesses are more abundant and events are more likely to be reported to the police. More reported crime could lead to more police even when there is no increase in the actual volume of crime. Higher population density also leads to higher levels of drug abuse, as reported by Flowers (1999, p. 68), who found that patterns of drug use, as indicated by urinalyses of male arrestees, were highest in urban areas.

Similarly, the percentage of home ownership has been found to be related to crime. In fact, Dietz (2003, p. 13) reports that home ownership is the second most important predictor of victimization after income. If the lack of home ownership leads to victimization, one would assume that police would have to increase crime control efforts as home ownership declined. Additionally, Page-Adams and Sherraden (1996) found that the children of homeowners are less likely to have alcohol and substance abuse problems. It could, therefore, be argued that fewer substance abuse problems in a community will have a direct effect on police organizational structure. 
Researchers have put forward a number of theories to explain why organizational characteristics affect police enforcement policies. They include rational systems theory (Scott, 1981), contingency theory (Lawrence \& Lorch, 1967), resource dependency theory (Pfeffer \& Salancik, 1978), racial threat theory (Blalock, 1967), and institutional theory (DiMaggio \& Powell, 1983). All are believed to affect the formal structure of police organizations.

\section{Rational Systems Theory}

Early management theorists viewed organizations as "rational systems" (Scott, 1981) designed for the efficient achievement of a group's goals. The rational systems perspective was at the heart of early twentieth century police reform. Weary of political interference and hoping to take advantage of advances in scientific management, police departments used rational systems theory to develop the professional model of policing. Sometimes called the reform model, the professional model of policing centralized authority, created specialized crime-fighting units, shifted officers from foot to motorized patrol, and introduced radio technology. Activities and personnel were organized by clientele, type of service, time of day, and geography, all to ensure the efficient delivery of police service. Rational systems theory would argue that specialized police drug units are a direct response to a demonstrated need-a response that is best addressed through differentiation and accountability.

\section{Contingency Theory}

Although contingency theory was originally envisioned as separate from rational systems theory, researchers have come to view it as complementary to the rational systems perspective (Greenwood, 2008, p. 51). What makes these two theories similar is the fact that they both argue that changes in the organization of work are directly related to changes in the task environment. The rational systems perspective holds that functional differentiation is a direct, bureaucratic response to a demonstrated need. Contingency theory differs in that it views an organization's response as a product of the proper fit between organizational design and environmental exigencies. Factors such as the size of a community, population composition, and the nature and extent of the crime problem may all influence the decision to modify an organization's structure (Kuykendall \& Roberg, 1982, p. 243). As such, contingency theory would argue that it may take more than a rational need to create a police drug enforcement unit.

\section{Resource Dependency Theory}

Resource dependency theory is also related to an organization's task environment, but differs from rational systems theory and contingency theory in its focus on structures and behaviors that sustain the flow of resources independent of the 
rational need. In other words, police departments are likely to create specialized units because resources are available from the state and federal government even though they may not have the designated crime problem. Although there is no resource dependency research bearing directly on the issue of police drug units, Maguire (1997, p. 554) found that the reason many police agencies implemented community policing was really to receive a share of the $\$ 8.8$ billion available from the federal COPS program--which allowed them to hire new police officers-and not necessarily a need for, or a commitment to, community policing.

\section{Racial Threat Theory}

Derived from the conflict paradigm, racial threat theory (Blalock, 1967) argues that whites perceive the increased presence and visibility of minority groups as both an economic and political threat. Liska and Chamlin (1984) extend this theory to include the threat of black crime. The threat of black crime hypothesis asserts that social control will increasingly be directed against blacks as their population grows larger in size and as black-on-white crime increases. Research following this tradition suggests that the racial threat hypothesis also affects police organization. In a sampling of 90 U. S. cities, Jackson and Carroll (1981, p. 303) found that police expenditures expanded when a minority group appeared threatening to the dominant population. In a similar study, Liska, Lawrence, and Benson (1981, p. 424) found that dramatic increases in police department size, during the late 1960s and early 1970s, could not be accounted for in terms of reported crime rates alone. Instead, they argue that these increases were influenced by the relative size of racially dissimilar groups associated with street crime.

\section{Institutional Theory}

Institutional theory, like resource dependency theory, argues that the structure and activities of an organization do not always reflect rational adaptations to environmental problems. Institutional theorists believe that the structure and activities of an organization reflect the values and beliefs of powerful actors called sovereigns (mayors, council members, special interest groups), who have the ability to influence the policies of the organization. Crank and Langworthy (1992, p. 338) applied institutional theory to policing, arguing that police departments in the United States are highly institutionalized organizations shaped by powerful myths in their environment. Myths are untested ideas and beliefs that many believe to be true. The incorporation of these accepted myths enables police departments to attain legitimacy. With legitimacy comes stability and protection from outside interference by powerful actors, who have the ability to shape the institutional environment. As such, institutional theory would argue that the establishment of a police drug unit could have more to do with the fact that police departments are expected to have a drug enforcement unit than the actual extent of the drug abuse problem in a community. 


\section{Research Question}

We hypothesize that there are specific features and characteristics of police organizations, and the communities they serve, that affect their decision to operate a police drug unit and participate in a multi-agency drug task force. We argue that the decision by police departments to employ these drug control strategies is a function of three general groups of factors including: 1) the organizational structure and characteristics of the law enforcement agency, 2) the size and characteristics of the population and jurisdiction served, and 3) the extent and nature of the drug and crime problem. Thus, the general models we intend to develop and use to test this hypothesis can be described as follows:

Model 1: Operation of a Full-Time Drug Unit $f$ [Agency Structure + Agency Resources \& Characteristics + Size of Jurisdiction + Population Characteristics + Drug and Violent Crime Problem]

Model 2: Per-Capita Officers Assigned to Drug Unit $f$ [Agency Structure + Agency Resources \& Characteristics + Size of Jurisdiction + Population Characteristics + Drug and Violent Crime Problem]

Model 3: Participation in a Multi-Agency Drug Task Force $f$ [Agency Structure + Agency Resources \& Characteristics + Size of Jurisdiction + Population Characteristics + Drug and Violent Crime Problem]

Model 4: Per-Capita Officers Assigned to a Multi-Agency Drug Task Force $f$ [Agency Structure + Agency Resources \& Characteristics + Size of Jurisdiction + Population Characteristics + Drug and Violent Crime Problem]

Summarized in the next section are the data sources and specific measures used to operationalize the dependent and independent variables described above.

\section{Data and Methods}

In order to examine this hypothesis, we obtained and combined data from three different and separate information sources: the 2003 Law Enforcement Management and Administrative Statistics (LEMAS) Survey, the 2000 Decennial Census, and the 2003 Uniform Crime Report (UCR) program. The LEMAS survey collects a wide variety of information from a representative sample of law enforcement agencies in the United States every three years, including information about staffing, budget, programs, and policies. LEMAS also collects data on the number of full-time officers assigned to drug enforcement units and the number assigned to multi-agency drug task forces. The strengths and weaknesses of using the LEMAS data as a platform for comparative research involving police departments is described in detail by Langworthy (2002). While Langworthy argues that LEMAS is an extraordinary vehicle for collecting police data, he recognizes that work is 
needed on calls for service, beat enumerations, and an explication of agency rank structure, none of which affect this analysis. In addition, data available from the 2000 Census were obtained and used to measure the characteristics of the population served by the police departments in the LEMAS sample, including resident age, race, and housing characteristics. Finally, data available from the UCR program provided information on the number of violent Index crimes reported to each of the police departments, as well as the number of arrests for drug law violations.

In order to match the data from the LEMAS survey, the Census, and the UCR, we used a cross-walk program provided by the Inter-University Consortium for Political and Social Research (ICPSR). This program allowed us to link the agency identification number used in the LEMAS survey with the Federal Information Processing Standards (FIPS) codes used in the Census, and the Originating Agency Identifier (ORI) codes used in the UCR data. Out of the 2,791 municipal and county police departments included in the 2003 LEMAS survey, our final sample consisted of the 2,425 (86\%) agencies for which we were able to obtain and merge both Census and UCR data.

\section{Dependent Variables}

As described earlier, our primary interest is in examining how the decision by local law enforcement agencies to operate a full-time drug unit or to participate fulltime in a multi-agency drug task force is related to the organizational structure and characteristics of law enforcement agencies, the size and characteristics of the population and jurisdiction served, and the extent and nature of the drug and crime problem. From the LEMAS survey, we created a dichotomous variable to indicate whether each agency included in our sample assigned one or more full-time officers to an in-house drug unit. The departments that did not have a full-time drug unit were coded as 0 in the analyses that follow, and departments that did have a full-time drug unit were coded as 1 ( 0 = no full-time drug unit, 1 = full-time drug unit). Similarly, data from the LEMAS survey were recoded to identify those departments in the sample that did and did not have at least one officer assigned full-time to a multi-agency drug task force $(0$ = no officers assigned full-time to a multi-agency drug task force, 1 = officers assigned full-time to a multi-agency drug task force). In addition to measuring the existence of an in-house drug unit or participation in a multi-agency drug task force (i.e., dichotomous measures), we also wanted to examine the relative amount of resources/officers committed to each of these drug control approaches. Thus, we also computed the percapita number of full-time officers assigned to an in-house drug unit and the per-capita number of full-time officers assigned to a multi-agency drug task force.

In order to produce the national estimates of drug unit operation and participation in drug task forces, Hickman \& Reaves (2006) used weighted responses to the LEMAS survey, resulting in a national estimate of $18 \%$ of all agencies having a drug unit and $23 \%$ of agencies participating in a multi-agency drug task force. Given our research questions, we did not weight the survey responses, and the unweighted data indicated that $41 \%$ of the local police departments contained in our sample main- 
tained a full-time, specialized drug enforcement unit, and $48 \%$ contributed full-time officers to multi-agency drug task forces. As seen in Table 1, the mean number of per-capita officers assigned to drug units by police departments in the sample was 4.6 per 100,000 residents, but the distribution was highly skewed. Similarly, the mean number of per-capita officers assigned to multi-agency drug task forces by police departments in the sample was 3.9, and was also highly skewed (Table 1).

\section{Operationalization of Independent Variables}

As our review has shown, organizational changes within a police department, and differences across departments, are related to a number of diverse factors, including agency resources, organizational characteristics, jurisdiction size, community characteristics, and the level of crime. The following summarizes the operationalization of the independent variables we included in the analyses within these categories. The descriptive statistics of each measure are presented in Table 1, along with the theoretical perspective each variable attempts to measure.

\section{Agency Resources}

We used LEMAS data to measure agency resources. Specifically, we measured agency resources by computing the per-capita budget for each agency using the LEMAS annual (2003) budget variable and Census data on the population served by the agency. As seen in Table 1 , across the 2,425 police agencies contained in our sample, the mean budget was $\$ 175$ per resident, although the distribution was positively skewed. The median per-capita expenditure was $\$ 148$. An alternative indicator of available resources-per-capita police officers-could also have been used; however, this measure was so highly correlated with per-capita expenditures that per-capita expenditures was chosen for the analyses to avoid redundancy and multicolinearity. ${ }^{1}$

\section{Organizational Characteristics}

We operationalized organizational characteristics by measuring the degree of agency formalization, centralization, and task specialization. We accomplished this by utilizing a number of different questions found in the LEMAS survey, including

\footnotetext{
${ }^{1}$ When the correlation between per-capita expenditures and officers per capita was examined, both Pearson's $r$ and Spearman's rho were high and statistically significant. Pearson's $r$ equaled .97, $p<.001$, and Spearman's rho equaled .71, $p<.001$. Due to the highly skewed nature of these measures, Spearman's rho is the more appropriate non-parametric test to measure correlation. When these data were weighted using the weights developed by the $\mathrm{Bu}$ reau of Justice Statistics to produce national estimates, the correlations were still exceedingly high and statistically significant: $r=.98, p<.001$, Spearman's rho $=.68, p<.001$.
} 


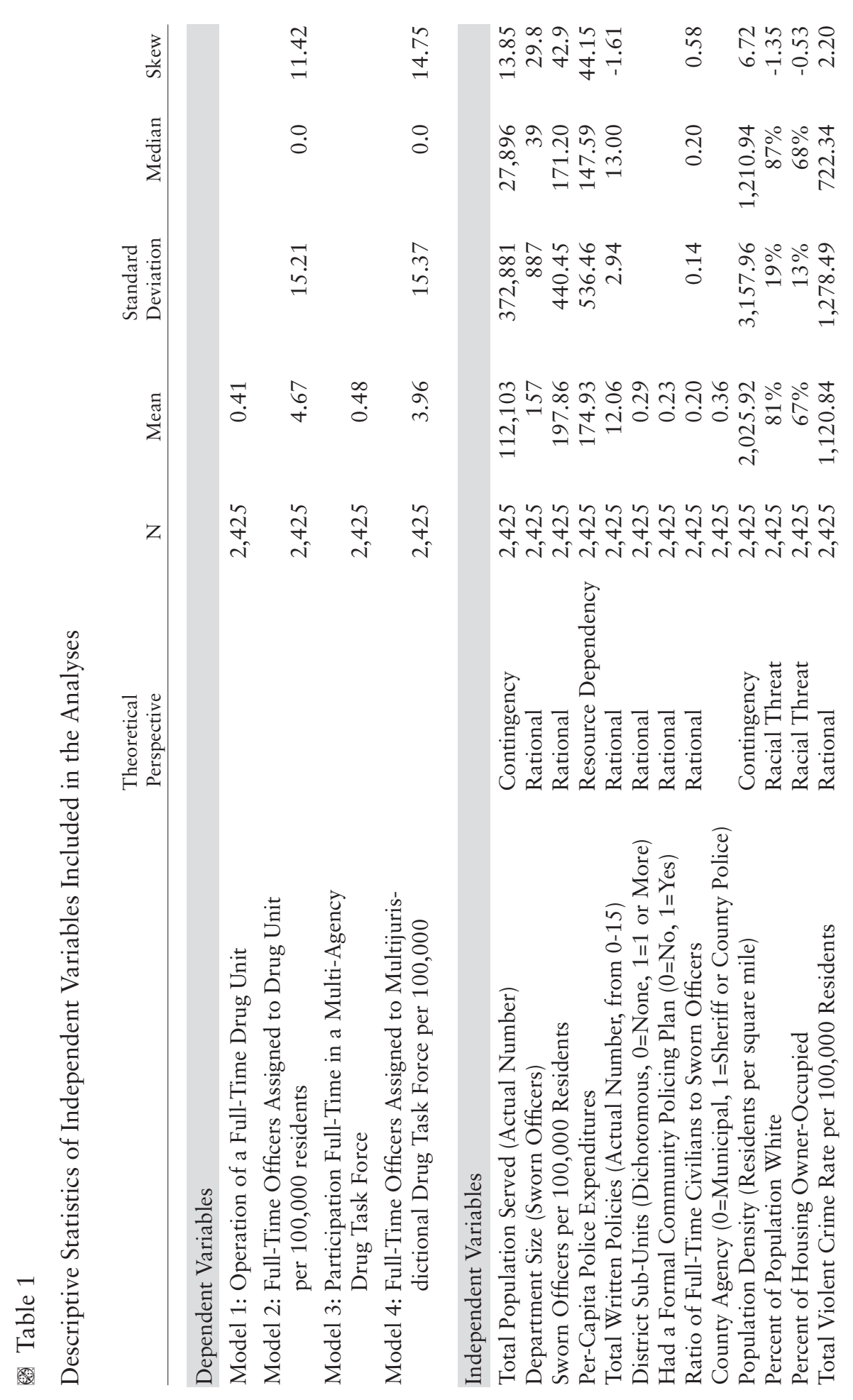


the number of formal written policies, the existence of separate policing districts or precincts, the existence of a formal community policing plan, and the proportion of agency employees accounted for by civilians, but we also recognize the concerns raised by Langworthy (2002) regarding the potential limitations of operationalizing these concepts from available LEMAS data.

Included in the LEMAS survey were questions that sought to determine the existence of formal, written policy directives for 15 different issues, ranging from the use of deadly force to interacting with the media. While these 15 issues represent a small number of items (Langworthy, 2002), they do cover a wide range of topics. Affirmative responses to the existence of these individual policies were totaled for each agency in the sample to produce one measure of the degree of agency formalization. As seen in Table 1, the mean number of written policies reported was 12 out of a possible 15. Roughly, $19 \%$ of the agencies included in the sample indicated that they had policies for all 15 of the specific questions asked in the LEMAS survey, and less than $10 \%$ of the sample indicated that they had fewer than 8 of the formal policies asked.

The degree of centralization/decentralization of police operations was measured using the LEMAS question regarding the number of districts, precincts, or division stations that the department operated separate from headquarters. The agency responses were recoded into a dichotomous variable, and as seen in Table $1,29 \%$ of the sample departments had one or more of these "district sub-units" operating separately from police headquarters. Whether or not the police departments in our sample had a formal community policing program was also used as a proxy for the degree of centralization/decentralization. As seen in Table 1, based on information reported to the LEMAS survey, $23 \%$ of the agencies included in our sample indicated that they did have such a plan.

The literature examining police organizational features points to the fact that higher degrees of task specialization are helpful in understanding how departments are organized and carry out their missions. Included in the LEMAS survey are questions regarding the operation of specific specialized units; however, these questions are only asked of a subset of agencies (referred to as the long form), and analyses of these responses suggest that larger agencies are more likely to receive the long form, resulting in a highly biased subsample. However, another measure that can be used to measure task specialization is the proportion of full-time employees accounted for by civilian personnel. These data were available for all agencies included in the sample we examined. As seen in Table 1, across the agencies included in the sample, the ratio of full-time authorized civilian personnel to fulltime authorized sworn officers averaged .20 to 1, indicating that across the sample there was roughly 1 full-time civilian for every 5 sworn officers.

The last agency characteristic we included in the analyses was a variable to distinguish between county/sheriff's offices and municipal police departments. County/sheriff's often serve as the "lead" law enforcement agency in each county, and may be responsible for a much wider array of law enforcement services, including drug enforcement. To distinguish between municipal police departments and 
county/sheriff's police departments, we coded municipal police departments 0 and county/sheriff's police departments as 1 . In our sample, just over one third (36\%) were county/sheriff's police departments and the remaining $64 \%$ were municipal departments (Table 1).

\section{Characteristics of the Jurisdiction and Population Served}

The literature and our hypothesized model suggest that the following characteristics influence the organizational responses and structure of police departments: the sheer size of the jurisdiction served, the population density of the community, and the population and housing characteristics. The following summarizes the sources of information used to measure these characteristics, and provides a summary of these characteristics for the sample of agencies included in our analyses.

Jurisdiction size was measured by using the total population of the jurisdiction served by the law enforcement agencies included in our sample. These data were derived from the 2000 census. Within our sample of 2,425 local law enforcement agencies, the average population served was just over 112,000, although the median was just under 28,000, illustrating the high, positive skew of the distribution.

We also measured the population density of the communities served by the law enforcement agencies in our sample by taking the total population divided by the square miles of the jurisdiction. As seen in Table 1 , the population density averaged 2,026 residents per square mile, and the median was just over 1,200 residents per square mile, again illustrating the high degree of positive skew in the distribution. To place this into context, the population density of cities like Chicago exceeds 12,000 residents per square mile, and smaller communities like Anchorage have a population density of fewer than 153 residents per square mile (2000 U.S. Census).

The percentage of the population accounted for by white residents in the communities served by each law enforcement agency was also included in the analyses. We computed this measure using data from the 2000 census. On average, across the agencies included in our sample, $81 \%$ of the residents were white, although the median was slightly higher $(87 \%$ ) (see Table 1 ). Further, only about $9 \%$ of the agencies included in our sample served a population where whites accounted for less than one half of the total population. We also obtained information from the 2000 Census regarding the number of housing units in each community that were owner-occupied. On average, $67 \%$ of the inhabited housing units were occupied by the owner of the property (Table 1$)$.

\section{Levels of Crime}

Information on the extent and nature of drug and violent crime was obtained from the UCR. Specifically, the reported violent crime rate (combining the number of murder, rape, robbery, and aggravated assault offenses) was computed, and averaged 1,121 offenses per 100,000 residents across the agencies included in our sample (Table 1), although the median violent Index offense rate was considerably lower, at 722 per 100,000 due to the high degree of skew in the distribution. In ad- 
dition, data regarding the number of drug arrests were also obtained through the UCR. However, because the reporting of arrest data, particularly arrest data for non-Index crimes (i.e., Part II offenses) is voluntary and not consistent, we were only able to obtain drug arrest data for 1,821 of the 2,425 agencies included in the LEMAS sample. Further analyses were performed to determine if there appeared to be any systematic bias or substantial differences between those agencies we were able to obtain drug arrest data for versus those for which data were not available. After comparing those agencies that reported drug arrest data to those that did not report drug arrest data, we found no statistically significant differences in terms of mean population, total officers, officers per capita, and per-capita police expenditures. Rather substantial and statistically significant differences were evident, however, when the violent crime rate was compared between those police departments that reported drug arrests and those that did not. Specifically, those that reported drug arrests had much higher violent crime rates than those that did not report drug arrests (mean of 1,329 per 100,000 and 494 per 100,000, respectively ( $\mathrm{F}=209, p<$ .001). Further, among those agencies that reported both violent Index offenses and drug arrests, there was a high correlation between violent crime and drug arrest rates (Spearman's rho $=.61, p<.001$ ). Thus, because of the potential sampling bias that would result from excluding those agencies that did not report drug arrests through the UCR, combined with the potential of introducing multicolinearity into our regression analyses due to the relatively high degree of correlation between the drug arrest and violent crime rates, we decided to use only the reported violent crime rate as an independent variable for the crime level in our analyses.

\section{Analytic Methods}

The methods of analyses used in the current research include both bivariate and multivariate analyses. Bivariate analyses were performed to examine the direction and strength of the statistical relationship between the dependent variables and the independent variables, as well as the degree of correlation among the independent variables. Because most of the variables displayed a high degree of skew (as summarized in Table 1), and all variables were either dichotomous or interval/ratio-level measures, Spearman's rho was used to examine the bivariate relationships among the variables (Table 2). For the multivariate analyses, logistic regression was used in the models to examine the relationship between the independent variables and the dependent variables measuring the existence of a drug unit/participation in a drug task force because of the dichotomous nature of these dependent variables (i.e., dichotomous variables indicating the presence or absence of a full-time drug unit-Model 1 -or participation in a drug task force-Model 3). Using logistic regression allowed us to statistically isolate the effect of each independent variable on the operation of a drug unit or participation in a drug task force, after statistically controlling for the influence of the other independent variables. Thus, the coefficients for the independent 
Table 2

Correlation Between Independent Variables \& Dependent Variables, Spearman's Rho

\begin{tabular}{l|l|l|l|l|l|l}
1 & 2 & 3 & 4 & 5 & 6 & 7
\end{tabular}

Independent Variables

1. Jurisdiction Size: Total Population Served

2. Per-Capita Police Expenditures

\subsection{0}

\begin{tabular}{l|l}
$0.01 \quad 1.00$
\end{tabular}

3. Per-Capita Officers

4. Total Written Policies (0-15)

5. District Sub-Units (Dichotomous, 0=None,

\begin{tabular}{ll} 
& $1=1$ or More $)$ \\
\hline 6. & Formal Community Policy \\
& Plan $(0=$ No, $1=$ Yes $)$
\end{tabular}

\section{2}

3

4

7

7. Ratio of Full-Time Civilian to Officers

8. County Agency ( $0=$ Municipal, $1=$ Sheriff or County Police)

9. Population Density (Residents per square mile)

10. Percent of Population White

11. Percent of Housing Owner Occupied

12. Total Violent Crime Rate per 100,000 Residents

\begin{tabular}{|l|l|l|}
\hline$-0.35 * *$ & $0.71 * *$ & 1.00 \\
\hline
\end{tabular}

\begin{tabular}{|r|r|}
\hline$-0.35 * *$ & 0.71 \\
\hline $0.35 * *$ & $0.26 *$ \\
\hline $0.42 * *$ & $0.08 *$ \\
& \\
\hline
\end{tabular}

\begin{tabular}{|l|l|l|l|}
\hline $0.29 * *$ & $0.21 * *$ & $0.10 * *$ & $0.32 * *$ \\
\hline
\end{tabular}

$0.31 * *$

\begin{tabular}{|l|l|l|}
\hline $0.16^{* *}$ & $-0.13^{* *}$ & $0.19 * *$ \\
\hline
\end{tabular}

$0.31 * *$

$-0.58 \%+2.0 .6$

$0.17^{* *}$

$0.50^{\circ+2}+0.3$

\begin{tabular}{|l|l|}
\hline$-0.41 * *$ & -0.28 \\
\hline$-0.27 * *$ & -0.35
\end{tabular}

te 0.1

\begin{tabular}{|c|c|c|c|c|c|c|}
\hline $0.11^{* *}$ & $0.45^{* *}$ & $0.49 * *$ & $0.19 * *$ & $0.10^{* *}$ & $0.20 * *$ & $0.10 * *$ \\
\hline$-0.14 * *$ & $0.51 * *$ & $0.54 * *$ & $0.12 * *$ & $-0.02 * *$ & $0.12 * *$ & $0.08^{* * *}$ \\
\hline
\end{tabular}

per 100,000

\section{Dependent Variables}

\section{Has Drug Unit} (0=No, $1=$ Yes $)$

15. Per-capita Full-Time Officers to Drug Unit

16. Participates in Task Force ( $0=$ No, $1=$ Yes)

17. Per-capita Full-Time Officers to Task Force

\begin{tabular}{|c|c|c|c|c|c|c|}
\hline $0.47^{* * *}$ & $0.17^{* * *}$ & $0.04 *$ & $0.22 * *$ & $0.27^{* * *}$ & $0.23 * *$ & $0.14^{* * *}$ \\
\hline $0.37 * *$ & $0.23 * *$ & $0.17^{* * *}$ & $0.20 * *$ & $0.23 * *$ & $0.22 * *$ & $0.11 * *$ \\
\hline $0.50 *$ & $0.11^{* *}$ & $-0.06 * *$ & $0.21 * *$ & $0.24 * *$ & $0.19 * *$ & $0.17 * *$ \\
\hline $0.30 * *$ & $0.13 * *$ & $0.05 *$ & $0.15 * *$ & $0.14 * *$ & $0.13^{* *}$ & $0.10 * *$ \\
\hline
\end{tabular}

$* p<.05, * * p<.01$ 


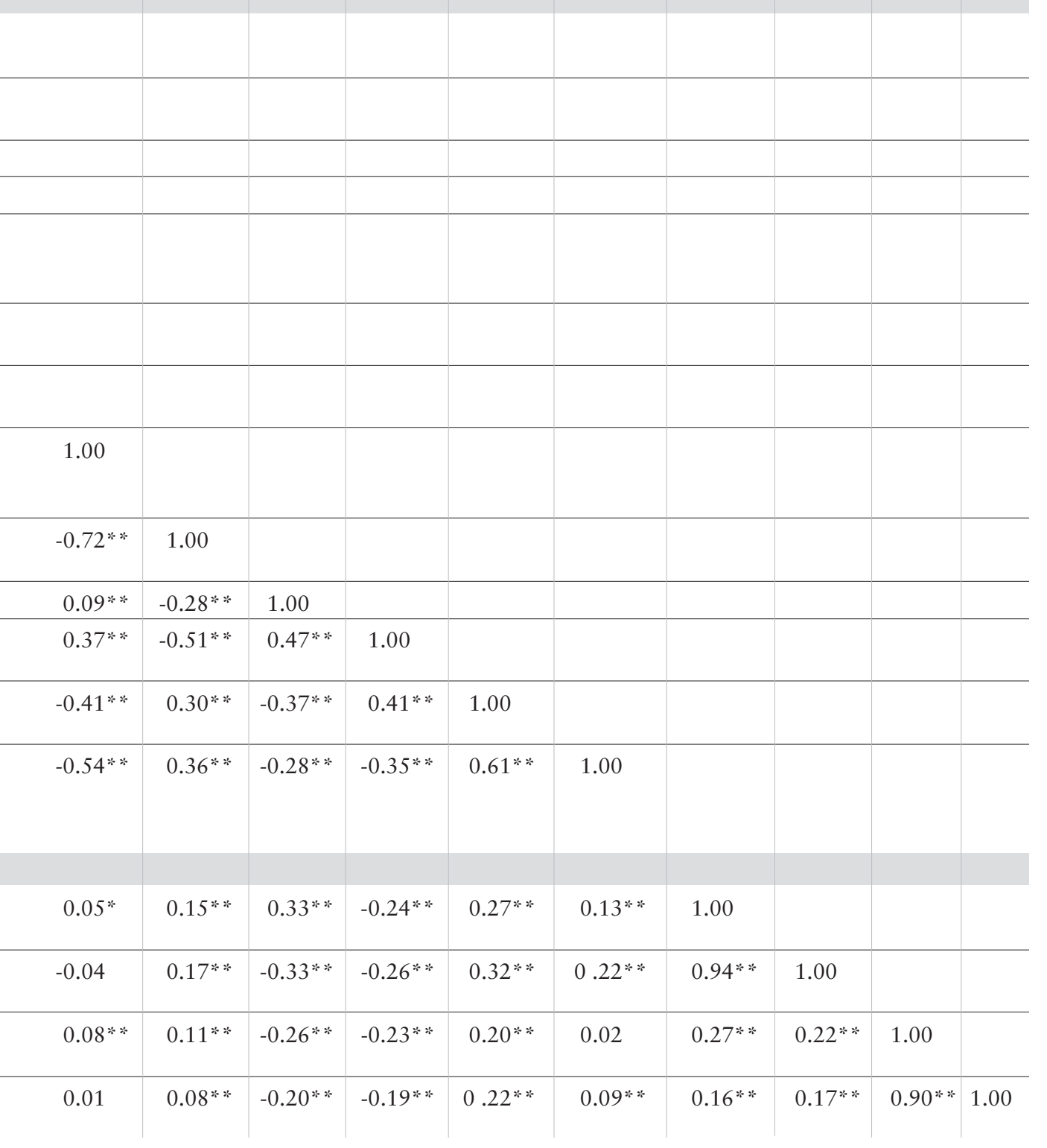


variables in the logistic regression models can be interpreted as indicating whether they increased, decreased, or had no influence on the likelihood that an agency would operate a drug unit or participate in a drug task force. For the analyses involving the dependent variables measuring the relative amount of resources committed to drug units and drug task forces (i.e., the per-capita number of full-time officers assigned to these activities, or Models 2 and 4), ordinary least squares (OLS) regression was used. Because these measures of per-capita officers assigned to drug units and drug task forces were so highly skewed, log transformations of these variables were performed. Thus, the coefficients for the independent variables in the OLS models can be interpreted as the change in the number of officers per capita assigned to drug units or drug task forces for each unit change in the independent variable.

Although it would have been ideal to perform the analyses using a panel design (i.e., a cross-section of agencies across multiple points in time), this was not possible because each wave of the LEMAS survey includes different agencies in its sampling methodology for agencies with fewer than 100 officers. While all agencies with 100 or more officers is included in each wave of the survey, the fact that smaller agencies (which may be less likely to operate drug units and participate in drug task forces) are samples prevents this temporal dimension of panel analyses. Thus, while King (2009) has called for a life-course (longitudinal) view of police organizational change, we are limited in this analysis to collecting data at one point in time. King's work describes six important stages in the evolution of police organizations: organizational birth, early founding effects, growth, decline, crisis, and death. Of the 14,254 law enforcement agencies in the United States, less than one half of one percent were begun since 1990 and it is not likely that a declining organization will take on a new responsibility (FBI, 2005). Therefore, we would argue that the police departments in our sample are in the growth or crisis stage of development. Finally, data are not readily available on when these units were formed or when multi-agency task force participation began.

\subsection{Results}

In general, the results of the bivariate analyses support the hypotheses regarding the existence and direction of the relationships between the independent variables and the dependent variables. Summarized in Table 2 are the results of our bivariate analyses, which not only identify a number of strong correlations between the independent variables and the two dependent variables using Spearman's rho, but also illustrate some of the potential areas of multicolinearity described above. ${ }^{2}$

${ }^{2} \mathrm{Of}$ all the independent variables identified, only two-ratio of civilian staff to officers and percent of owner-occupied housing-had distributions that were not highly skewed (Table 1). For these, the correlation with the dependent variables employed Pearson's $r$. 
Overall, there were statistically significant correlations, ranging from weak to strong, between almost all of the independent variables and the four dependent variables. Given the size of the sample involved, the fact that there were statistically significant correlations is not surprising.

Summarized in Table 3 are the results of the two multivariate models examining the factors associated with the operation of a full-time drug unit within departments (Model 1) and the relative amount of resources devoted to drug units within departments (Model 2). Overall, there were generally consistent patterns seen between the two models both in terms of the existence of a statistically significant relationship, the direction of the relationships, and which variables appeared to have the largest influence on the dependent variable. Below is a more detailed description and interpretation of the results presented in Table $3 .^{3}$

With respect to the first variable - the total population served by the agencythe multivariate analyses for Model 1 (existence of a drug unit) confirmed that the larger the population of the jurisdiction, the more likely agencies were to have a full-time drug unit, after statistically controlling for the other variables included in the model. However, population size did not have a very strong relationship relative to the other variables, as indicated by the relatively small Wald statistic (3.97). ${ }^{4}$ Further, population size did not have any statistical relationship to the number of officers per capita assigned to drug units (Model 2). Thus, while population size has some influence on the existence of drug units, it is much smaller than indicated in the bivariate analyses and relative to other factors, and it did not have any independent relationship with the per-capita number of officers assigned to drug units. This same pattern was evident when participation in multi-agency drug task forces was considered (Models 3 and 4): Population was associated with participation in

The correlation between full-time drug unit and ratio of civilian to sworn officers was $r=$ $.08, p<.001$, and the correlation between full-time drug unit and percent of owner-occupied housing was $-.25, p<.001$. The correlation between full-time participation in a drug task force and ratio of civilian to sworn officers was $r=.12, p<.001$, and the correlation between full-time participation in a drug task force and percent of owner-occupied housing was $-.22, p<.001$. Thus, the appropriate measure of correlation for all the remaining variables was Spearman's rho, which is presented in Table 2.

${ }^{3}$ When the same models presented in Table 3 were rerun and weighted using the weights developed by the Bureau of Justice Statistics to produce national estimates, the general results did not change (i.e., the same variables remained statistically significant, the directions of the relationships remained the same, and there was consistency in terms of which variables displayed the strongest relationships to the dependent variables).

${ }^{4}$ The Wald statistic can be used to determine relative strength of variables in a logistic regression model, particularly when the independent variables have different levels of measurement. Further, when the variables included in Model 1 were entered using forward stepwise regression, the addition of the population variable increased the Nagelkerke R2 by less than .01 . 


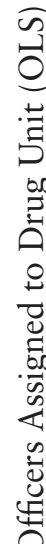

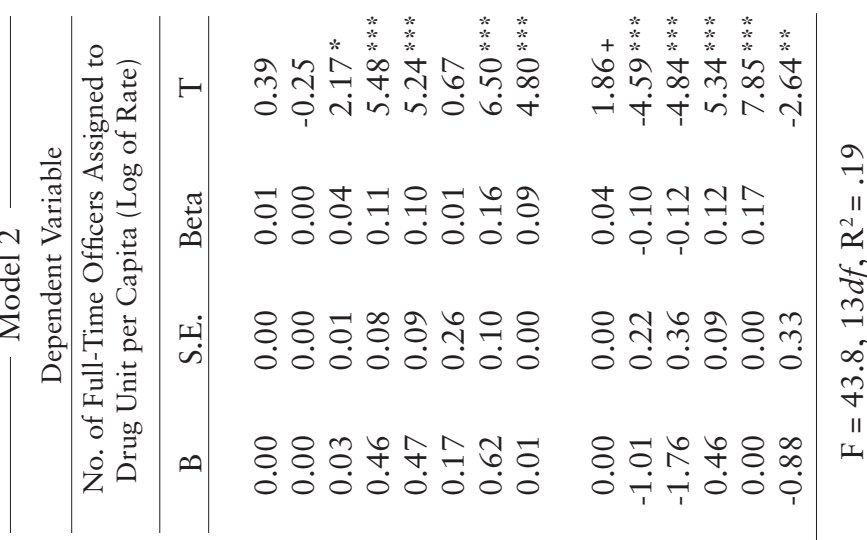

至

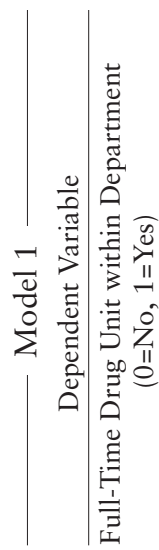

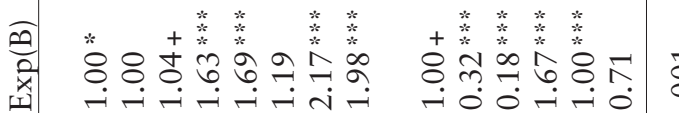

离

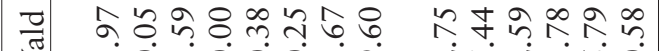

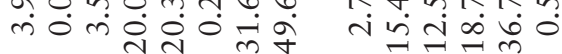

मㄹ

.⿹丁口⿹

क.

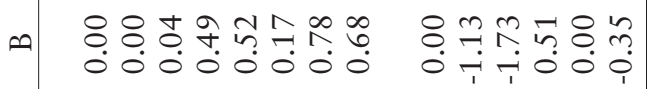

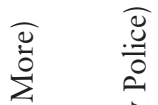
II

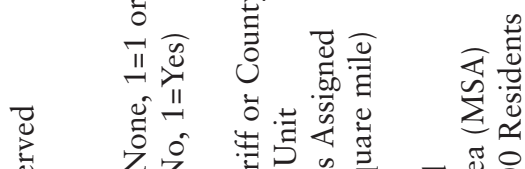

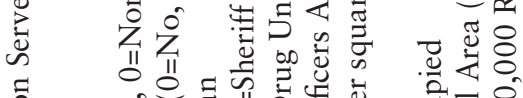
ㅎ.

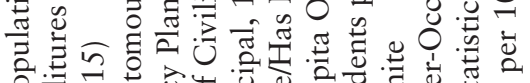
ồ.

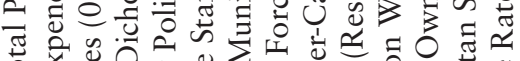

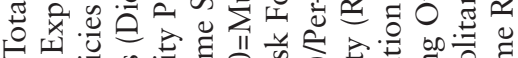
نั

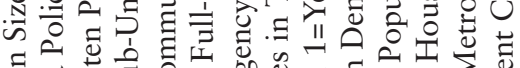
हี. 
multi-agency drug task forces, but had no relationship to the per-capita number of officers assigned by departments to these task forces (see Table 4). Similarly, the magnitude of effect the population variable had regarding participation in a drug task force (Model 3) was small relative to the other variables included in the model.

On the other hand, the indicator of relative police resources (operationalized as per-capita police expenditures) was not statistically associated with either the operation of a full-time drug unit (Model 1), per-capita officers assigned to drug units (Model 2), participation in a multi-agency drug task force (Model 3), or percapita officers assigned to drug task forces (Model 4), after statistically controlling for the influence of the other variables included in the model. Thus, while per-capita expenditures were positively associated with all of these measures in the bivariate analyses, relative resources available was not associated with any of the measures of drug enforcement effort once other variables were statistically controlled.

Among the variables used to operationalize organizational characteristicsthe degree of organizational formality, centralization, and the type of agency (i.e., county vs. municipal)—all were statistically significant predictors of the dependent variables in all four models. For example, as the number of formal written policies (an indicator of the degree of formality) increased, the more likely agencies were to operate a drug unit, allocate more officers per capita to drug units, participate in a multi-agency drug task force, and allocate more officers per capita to drug task forces. Similarly, departments that were decentralized (i.e., had subdistricts/precincts or had community policing plans) were more likely to operate a drug unit, allocate more officers per capita to drug units, participate in a multi-agency drug task force, and allocate more officers per capita to drug task forces, after statistically controlling for the other variables included in the model. For example, those departments that had one or more police districts or precincts were more likely to have a drug unit (odds ratio of 1.63) (and allocate more officers per capita to drug units [coefficient of .46]), and were more likely to participate in a drug task force (odds ratio of 1.49) (and allocate more officers per capita to drug task forces [coefficient of .31]) than those departments with no police districts or precincts. On the other hand, one of the proxy measures for task specialization-the ratio of civilian staff to sworn officers-did not reveal a statistically significant, independent relationship with the measures of drug unit operation (Models 1 and 2), but was a statistically significant predictor of an agency's participation in a multi-agency drug task force (Models 3 and 4).

The type of local law enforcement agency (county versus municipal) also predicted the operation and the number of officers allocated per capita for both drug units and task forces, with county-level agencies being more likely than municipal departments to operate a drug unit, allocate more officers per capita to those units, participate in a drug task force, and allocate more officers per capita to those task forces, after statistically controlling for all of the other variables in the models. Further, based on the Wald statistic (in logistic Models 1 and 3), and the standardized beta (in OLS Models 2 and 4), whether the agency was a county or municipal 


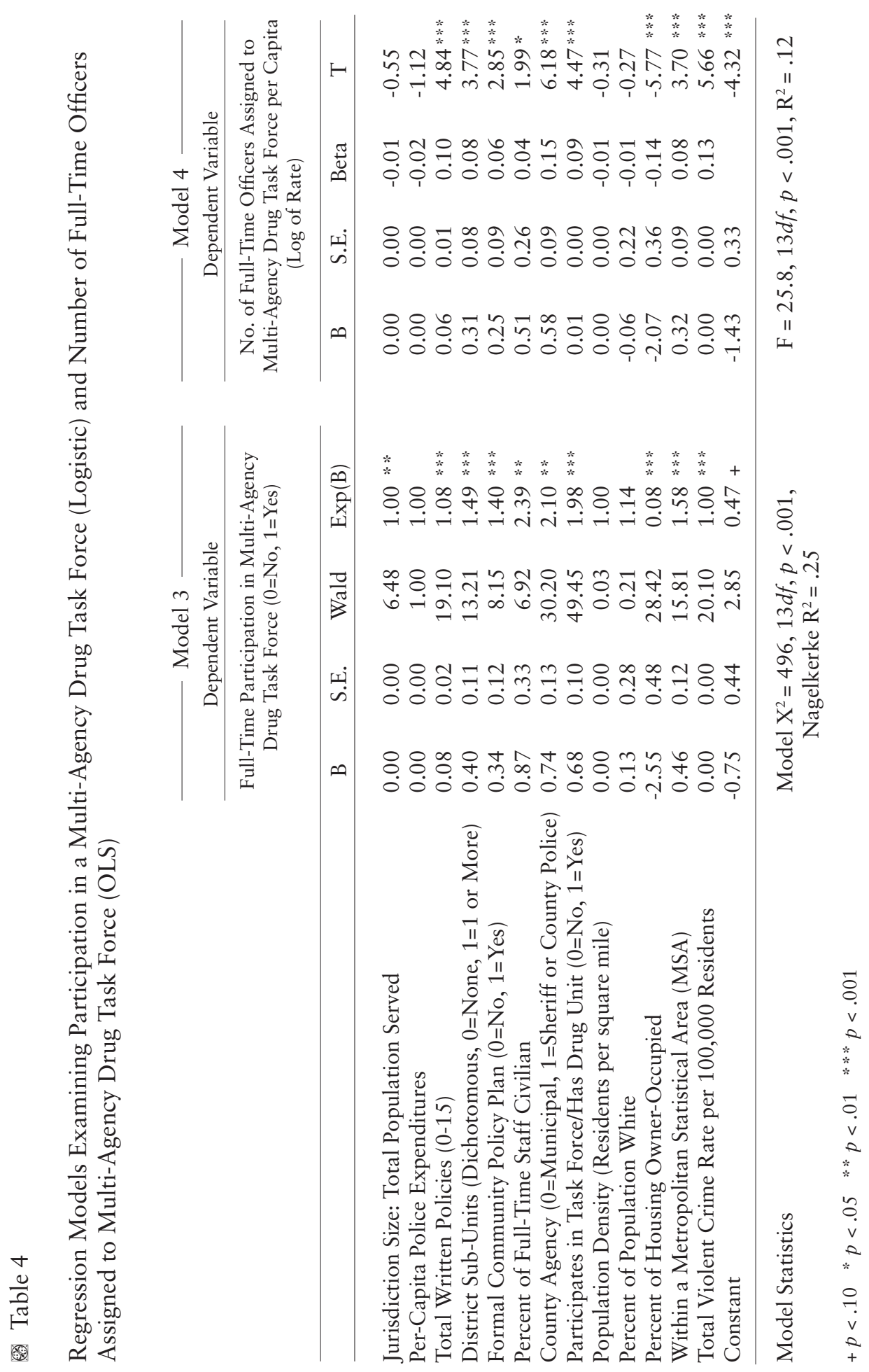


department had one of the strongest independent correlations to the dependent variables in all four models.

The models also reveal a clear relationship between the two approaches to drug enforcement (in-house drug unit and participation in a multi-agency drug task force): the existence/magnitude of one approach was positively associated with the existence/magnitude of the other approach. In other words, agencies that operated their own drug unit were more likely to participate in a multi-agency drug task force, and the more officers they assigned per capita to one approach, the more officers they assigned per capita to another approach. In fact, in Models 1 and 3 (measuring the existence of a drug unit and participation in a multi-agency drug task force), these were the strongest predictors among the variables included in the analyses (Wald of 49.6 and 49.4 , respectively).

Although the findings were relatively consistent in terms of agency characteristics being associated with both the operation of a drug unit and participation in a drug task force, when community population characteristics were examined relative to the operation of drug units and participation in drug task forces, some fairly substantial differences were evident. For example, the measures of percent of the resident population accounted for by whites and percent of housing that was owner-occupied were both statistically associated with the operation of a drug unit (Model 1) and the number of officers per capita assigned to drug units (Model 2) after statistically controlling for the other variables in the models. Specifically, the larger the proportion of the population accounted for by whites and the larger the percent of owner-occupied housing, the lower the likelihood of operating a drug unit (as indicated by the negative sign of the coefficient and the odds ratio being less than 1.0 in Model 1), and the fewer officers per capita assigned to these units (Model 2). On the other hand, the percent of the population accounted for by whites had no statistically significant relationship to an agency's participation in a multi-agency drug task force (Model 3) or the number of officers per capita assigned to these task forces (Model 4) after statistically controlling for the other variables included in the models. As with in-house drug unit operations, the higher the percent of owner-occupied housing, the lower the likelihood of participating in a drug task force (Model 3), and the fewer officers per capita assigned to these task forces (Model 4).

A consistent pattern was noted between the variable indicating if the agency was within a Metropolitan Statistical Area (MSA) and their drug enforcement efforts: agencies within an MSA were more likely to operate a drug unit and allocate more officers per capita to these units, and were more likely to participate in a drug task force and also allocate more officers per capita to these task forces. Also, population density had no statistically significant association in any of the models.

Finally, the violent crime rate was also positively related to all four measures of drug enforcement effort (Models 1 through 4). Departments experiencing higher rates of violent crime were more likely to operate a drug unit, allocate more officers per capita to these units, participate in a multi-agency drug task force, and 
allocate more officers per-capita to these task forces than those with lower violent crime rates. The violent crime rate had the strongest (Model 2) or second strongest (Model 1) relationship to the dependent variables examining in-house drug units (based on the Wald and standardized beta), and in the models examining multiagency drug task force participation (Models 3 and 4), the strength of the violent crime rate was among the top four strongest in each model.

\section{Discussion and Conclusions}

Drug law enforcement has become one of the primary duties of local police agencies in the United States, and arrests for drug law violations account for a substantial proportion of arrests made by these agencies (i.e., $13 \%$ of all arrests reported to the FBI in 2007 were for drug offenses). In response, police departments throughout the nation have considered the formation of specialized drug enforcement units and participation in multi-agency drug task forces as possible ways to respond to this challenge, but a relatively small percent of agencies operate drug units or participate in multi-agency drug task forces. Using data from 2,425 local law enforcement agencies, we examined the factors related to police departments operating specialized drug enforcement units and/or participating in multi-jurisdictional drug task forces. Generally speaking, we found a number of characteristics predictive of these decisions by local law enforcement administrators and policy makers, many of which are consistent with the varied literature on police organizational structures. However, the overall explanatory power of the variables included in the analyses was quite limited, which may suggest more nuanced and idiosyncratic forces behind the formation and staffing of these drug enforcement efforts.

Still, the research provides some insight into the extent to which local law enforcement agencies engage in these specific approaches to drug control, and the number of officers they assign to these efforts. By far the most influential variables in the analyses to explain the approach agencies take in terms of drug enforcement was whether the agency participated in other drug enforcement efforts (drug unit or task force), if the agency was county-level, the level of violent crime, and organizational formality and decentralization. Importantly, jurisdictions with higher levels of violence were more likely to operate their own specialized drug enforcement units and participate in drug task forces, and allocate more officers per capita to these efforts, which supports rational systems theory. Because of the difficulty associated with reliably measuring the extent and nature of a drug problem within a community, for both researchers and practitioners, agencies are likely to use the next best proxy for this-reported crimes of violence-when making decisions about resource allocations.

Similarly, we found measures of organizational formality and decentralization to be predictive of operating drug units and participation in drug task forces. 
These characteristics generally give rise to increasing differentiation and play a crucial role in determining organizational structure and task differentiation. However, contrary to our expectations, available resources (as measured by per-capita police expenditures) were not associated with either drug enforcement response by local law enforcement agencies: Just having more money per capita to spend did not translate into police departments' being more or less likely to operate a drug unit or participate in a drug task force, or allocate more officers to these efforts. Thus, we found no evidence to support resource dependency theory: Wealthy police departments were no more or less likely to establish a drug enforcement unit or participate in a drug task force, or allocate more officers, than poorer departments when other variables were statistically controlled.

Further, the multivariate analyses reveal the importance of not relying exclusively on bivariate analyses or single measures of drug enforcement effort. For example in the bivariate analyses, the size of the jurisdiction served (population) had the strongest correlation with the operation of in-house drug units; however, the multivariate analyses revealed that the strength of population as an explanatory variable was relatively weak once the other variables were taken into account. Further, while population size was predictive of the existence of a drug unit/participation in a multi-agency drug task force (i.e., the dichotomous measures in Models 1 and 3), population size had no independent relationship to the magnitude of effort (i.e., the per-capita officers assigned to a drug unit/task force, Models 2 and 4).

We also found that county-level agencies were more likely to operate their own drug unit and participate in multi-agency drug task forces. Part of this may be attributable to the fact that county police agencies (i.e., sheriff's offices) oftentimes serve as the lead law enforcement agency within a county, and therefore not only participate in multi-agency drug task forces, but also may take the lead in forming these task forces. The finding that agencies operating drug units were more likely to participate in multi-agency drug task forces may simply be an indication of a multifaceted approach to drug enforcement, or may reveal a more complex organizational structure or process related to having officers assigned to multi-agency operations. For example, organizationally or for supervisory purposes, some agencies that assign officers full-time to multi-agency task forces may also have them designated internally as being within a specialized drug unit, but for practical purposes their work is tied to a multi-agency drug task force.

Finally, we also found support for the argument that the operation of a drug unit within a police department, and how extensively that unit was staffed, may be associated with the characteristics of the population served, even after statistically controlling for factors such as population density, jurisdiction size, agency characteristics, and crime levels. For example, racial threat theory would support the hypothesis that the larger the proportion of residents who are white, the less likely police departments would need to "protect" against racial threat through the formation of specialized units, such as drug units, or the number of officers assigned to these activities. Although we did not find any relationship between the 
community's racial profile and participation in a multi-agency drug task force, we did find the racial characteristics of the population served to be associated with the operation of a full-time drug unit within local police departments (Model 1) and the number of officers per capita assigned to these units (Model 2). A similar pattern was found with owner-occupied housing, which may lend support to the theory that an increase in the proportion of residents who are seen as criminogenic would lead to more of a need for a formalized, and extensive, police response to the threat. Thus, as the proportion of housing units lived in by owners increases (i.e., fewer renters and more people committed to the community), the operation of drug units within departments, participation in drug task forces, and officers assigned to these activities decreases.

In conclusion, this first attempt to understand the role of organizational and community characteristics in the decision by local law enforcement agencies to operate their own full-time drug unit and/or participate in a multi-agency drug task force, and how many officers they assign to these functions, has provided some important findings and can, hopefully, lay the foundation for future analyses. One of the biggest limitations with the current analyses is the inability to measure the extent and nature of the drug problem across the communities included in the sample. Part of this is due to the limited, and apparently non-representative, reporting of drug arrests by local law enforcement agencies to the UCR program. However, even if there is more complete reporting, the degree to which drug arrests would be a reliable and valid measure of a community's drug problem, or just an indicator of differential law enforcement focus or effectiveness, would remain an unanswered question. In addition, despite using 13 different independent variables from multiple sources and measuring unique characteristics of police departments and jurisdictions served, the overall explanatory power of the multivariate models was quite low. This would suggest that understanding the formation and staffing of these types of drug enforcement efforts by local police departments may require in-depth case studies and qualitative methods to more fully reveal the forces behind these decisions. 
Blalock, H. (1967). Toward a theory of minority-group relations. New York: John Wiley.

Blau, P. (1970). A formal theory of differentiation in organizations. American Sociological Review, 35, 201-218.

Bureau of Justice Statistics. (2001). Drugs and crime facts. Washington, DC: U. S. Department of Justice. Retrieved February 2, 2009, from http://bjs.ojp.usdoj.gov/.

Bureau of Justice Statistics. (2005). Estimated drug arrests. Key Facts. Retrieved February 2, 2009, from http://bjs.ojp.usdoj.gov/.

Crank, J., \& Langworthy, R. (1992). An institutional perspective of policing. The Journal of Criminal Law and Criminology, 83, 338-363.

Coldren, J. (1993). Drug control task forces: Creating and implementing a multijurisdictional unit. Washington, DC: U.S. Department of Justice.

Dietz, R. (2003). The social consequences of home ownership. Columbus, $\mathrm{OH}$ : Center for Urban and Regional Analysis.

DiMaggio, P., \& Powell, W. (1983). The iron cage revisited: Institutional isomorphism and collective rationality in organizational fields. American Sociological Review, 48, 147-160.

Dunworth, T., Hayes, P., \& Saiger, A. (1997). National assessment of the Byrne formula grant program. Washington, DC: U.S. Department of Justice.

Federal Bureau of Investigation. (2005). Crime in the United States 2004. Washington DC: U.S. Department of Justice. Retrieved December 10, 2009, from http://www.fbi.gov/ucr/cius_04/.

Federal Bureau of Investigation. (2007). Crime in the United States 2006. Washington, DC: U.S. Department of Justice. Retrieved February 2, 2009, from http://www.fbi.gov/ucr/cius2006/index.html.

Flowers, R. (1999). Drug abuse and criminality in American society. Jefferson, NC: McFarland.

Greenwood, H. (2008). Organizations: Management without control. Thousand Oaks CA: Sage.

Harries, K. (2006). Property crimes and violence in the United States: An analysis of the influence of population density. International Journal of Criminal Justice Sciences, 1(2). Retrieved February 2, 2009, from http://cjsjournal.brinkster.net/harries.html.

Hickman, M., \& Reaves, B. (2002). Police departments in large cities, 1990-2000. Washington, DC: Bureau of Justice Statistics. 
Hickman, M., \& Reaves, B. (2006). Local police departments, 2003. Washington, DC: Bureau of Justice Statistics.

Jackson, P., \& Carroll, L. (1981). Race and the war on crime. American Sociological Review, 46, 290-305.

Katz, C. (2001). The establishment of a police gang unit: An examination of organizational and environmental factors. Criminology, 39, 37-73.

King, W. (2009). Toward a life-course perspective of police organizations. Journal of Research in Crime and Delinquency, 46, 213-244.

Kuykendall, J., \& Roberg, R. (1982). Police organization and management: Behavior lessons from America's best-run companies. New York: Warner.

Langworthy, R. (2002). LEMAS: A comparative organizational research platform. Justice Research and Policy, 4, 21-38.

Lawrence, P., \& Lorch, J. (1967). Organization and environment: Managing differentiation and integration. Boston: Harvard University Press.

Liska, A., \& Chamlin, M. (1984). Social structure and crime control among macrosocial units. American Journal of Sociology, 90, 383-395.

Liska, A., Lawrence, J., \& Benson, M. (1981). Perspectives on the legal order: The capacity for social control. American Journal of Sociology, 87, 413-426.

Maguire, E. (1997). Structural change in large municipal police organizations during the community-policing era. Justice Quarterly, 13, 547-576.

Mumola, C., \& Karberg, J. (2006). Drug use and dependence, state and federal prisoners, 2004. Washington, DC: U. S. Bureau of Justice Statistics. Retrieved February 2, 2009, from http://bjs.ojp.usdoj.gov/index.cfm?ty=pbdetail\&iid=778.

Office of National Drug Control Policy. (2004). The economic costs of drug abuse in the United States, 1992-2002. Washington, DC: Author.

Olson, D. (2005). Specialized drug units: Strategies for local police departments. In P. Phillips (Ed.), Policing and special units (pp. 181-198). Saddle River, NJ: Prentice Hall.

Page-Adams, D., \& Sherraden, M. (1996). What we know about the effects of asset holding: Implications for research on asset-based anti-poverty initiatives (Working Paper 96-1, Center for Social Development). St. Louis, MO: Washington University.

Pfeffer, J., \& Salancik, G. (1978). The external control of organizations: A resource dependency perspective. New York: Harper and Row.

Ratcliffe, J., \& Guidetti, R. (2008). State police investigative structure and the adoption of intelligence-led policing. Policing: An International Journal of Police Structure and Management, 31, 109-128. 
Reaves, B., \& Goldberg, A. (2000). Local police departments, 1997. Washington, DC: Bureau of Justice Statistics.

Scott, W. (1981). Organizations: Rational, natural and open systems. Englewood Cliffs, NJ: Prentice Hall.

Spiess, M., \& Fallow, D. (2000). Drug-related crime. Washington, DC: Drug Policy Information Clearinghouse, Office of National Drug Control Policy. Retrieved February 2, 2009, from www.whitehousedrugpolicy.gov/publications/ pdf/ncj181056.pdf.

Wickersham Commission on Law Observance and Enforcement. (1931). Report on the enforcement of prohibition laws in the United States. Washington, DC: U. S. Government Printing Office.

Worrall, J., \& Kovandzic, T. (2008). Is policing for profit? Answers from asset forfeiture. Criminology and Public Policy, 7(2), 219-244. 
Dr. Robert M. Lombardo, a sociologist, is an Assistant Professor of Criminal Justice and a member of the Graduate Faculty at Loyola University, Chicago. Dr. Lombardo was appointed to the faculty in 2005. He received his $\mathrm{Ph}$. $\mathrm{D}$. from the University of Illinois, Chicago in 1994. His dissertation, Recruitment into Organized Crime: A Study of Social Structural Support of Deviance, earned the prestigious Hans Mattick Award, presented by the Illinois Academy of Criminology, for outstanding contributions to criminal justice research.

Dr. Lombardo is a 35-year police veteran, having served 30 years with the Chicago Police Department and 5-years as the Deputy Chief of the Cook County Sheriff's Police Department. He has worked in all areas of policing including patrol, investigations, narcotics, administration, and organized crime. In addition, Dr. Lombardo has taught, as a visiting scholar, at the Chicago Police Academy and the Illinois State Police Academy.

Dr. Lombardo was appointed in 2000 by Illinois Governor George Ryan to serve on the Illinois Wireless Enhanced 911 Board and was a member of the Cook County Emergency Telephone Systems Board from 1997 to 2001. He also served as a consultant to the Illinois Integrated Justice Information Systems Implementation Board from 2002 to 2005.

Dr. Lombardo has served as a peer reviewer and guest editor for the Journal of Contemporary Criminal Justice and a book reviewer for the American Journal of Sociology. He has recently completed a book titled: The Black Hand: Terror by Letter in Chicago.

Dr. David Olson is Chairman and Associate Professor of Criminal Justice at Loyola University Chicago, and a member of Loyola's graduate faculty. Dr. Olson served as the Director of the Forensic Science Program at Loyola University from 2006 to 2008. For nearly 20 years, Dr. Olson worked at the Illinois Criminal Justice Information Authority, serving as a senior scientist and director of Illinois' Statewide Drug and Violent Crime Control Strategy Impact Evaluation Program, where he oversaw the evaluation and monitoring of federally funded drug control efforts in the state. He has also served as staff to the Illinois Governor's Task Force on Crime and Corrections (1993), the Illinois Legislative Committee on Juvenile Justice (1996), the Illinois Truth-in-Sentencing Commission (1997), and the Governor's Public Safety and Reentry Working Group (2005), and recently received gubernatorial appointments to the Advisory Boards of the Illinois Department of Corrections and the Illinois Department of Juvenile Justice.

Dr. Olson's most recent research has been published in the Journal of Experimental Criminology, Law and Human Behavior, The Journal of Law and Economics, and Justice Research and Policy. His current grant-funded research is 
examining drug treatment programs within Illinois' prisons, the impact of Truthin-Sentencing, and capital punishment reforms in Illinois.

Dr. Olson received his B.S. in criminal justice from Loyola University, Chicago, his M.A. in criminal justice from the University of Illinois at Chicago, and his $\mathrm{Ph} . \mathrm{D}$. in political science/public policy analysis from the University of Illinois at Chicago, where he was the recipient of the Assistant United States Attorney General's Graduate Research Fellowship. 
